Action research involves researchers and practitioners in collaborative projects and provides a means of integrating evaluation into the reform process.

\title{
Using Action Inquiry to Address Critical Challenges
}

\author{
Edward P. St. John, Jeffrey S. McKinney, Tina Tuttle
}

Strategies for using research as a basis for organizational reform in higher education have evolved over the past half-century, from total systems approaches to complex strategies that combine central and decentralized action. To put in context the inquiry process used in the Indiana Project on Academic Success (IPAS), this chapter first reconsiders the history of organizational reform efforts in higher education. Next, the inquiry approach itself is described, followed by a summary of the current status of the IPAS project and a few examples of the ways campuses have responded to this process approach to change.

\section{Situating Action Inquiry}

Using research to inform large-scale systemic approaches to change in higher education first gained momentum in the master planning movement of the 1960s (Halstead, 1974). Planning, budgeting, and evaluation systems were among the early attempts to organize universities using research and evaluation as an integral part of the change process (Weathersby and Balderston, 1972), an approach that evolved from the Allied war effort in World War II. Modern management methods, including operations research, were

Note: The project described in this chapter was funded by Lumina Foundation for Education. The opinions expressed in this chapter are the authors' and do not necessarily reflect policies or positions of the foundation.

\section{(3)WILEY}

\section{InterScience}


introduced into universities in the early 1970s (Balderston, 1974), largely in response to budgetary problems. These methods alleviated some of the financial tension of the period (Balderston, 1974; Cheit, 1974) but did not noticeably change academic or student affairs programs.

In fact, formal systems approaches often did not work well in higher education, given the decentralized nature of academic governance. In the early 1980s, a variety of strategic planning approaches emerged as a means of assessing context, envisioning new forms of action, and reorganizing academic units and programs (Chaffee, 1983; Keller, 1983; Norris and Poulton, 1987). For more than two decades, strategic methods for organizing and guiding the change process have been widely used in higher education. However, systematic evaluative research has not kept up with the changes on the planning side of the enterprise.

There is, of course, a long history of assessment methods (for example, Banta, Rudolph, Van Dyke, and Fisher, 1996), but these methods, too, have focused on the front end of change, responding to accountability systems and funding criteria. However, the evolution of these methods has not generated many evaluations of the reform efforts. It is possible that the adaptive change model that has evolved in higher education-using strategic methods to scan research to inform adaptive changes-works to address many of the challenges that come up. These adaptive and strategic change processes can be quicker than inquiry-based approaches because evaluation takes time.

Efforts to improve retention have also implicitly used this strategic approach. Interventions have evolved based on an understanding of the research, but evaluations of those interventions are rare (as discussed in Chapters One and Two of this volume). This situation is a reflection of the strategic orientation, looking at research as part of the initial phase of change and adapting organizationally. However, leaving evaluation out of the change process inhibits learning and adaptation.

While strategic action may be appropriate for mission-oriented planning and for adaptive changes, it may not be the best approach to solving the most serious problems. Habermas $(1984,1987,1991)$ distinguishes between two forms of action: strategic and communicative. Strategic action focuses on achieving goals; communicative action aims to build understanding. When there are recurrent problems with causes that are not readily apparent, we need to build an understanding of underlying causes before charging uncritically ahead with solutions that may not fit the problem. In higher education, not searching for causes is particularly problematic because most of the research is based on traditional-age students and traditional institutions. However, the most critical challenges often involve addressing the educational needs of nontraditional populations, like work students. Identifying strategies for improving opportunity for students who do not fit the traditional profile may require stepping off well-traveled paths.

There are critical challenges that have lingered unresolved at most campuses. Frequently, these challenges include issues related to diversity and 
the needs of new entrants. As Carter's review in Chapter Three of this volume illustrates, the efforts to improve opportunity for students of color have focused on student engagement and orientation. We would expect this to be so, given the research emphasis on engagement. However, analyses of persistence by students of color in Indiana, at least, revealed serious problems within academic fields. In a study of the Indiana cohort who graduated from public high schools in 2000 and enrolled in Indiana colleges the next academic year, St. John, Carter, Chung, and Musoba (2006) examined the impact of academic preparation, student aid, and college academic experience on persistence in college by African Americans, Hispanics, and whites and reached the following conclusion:

\begin{abstract}
There were substantial differences in the association between major choices and persistence across the three groups. For whites and Hispanics a few majors were positively associated with persistence. However, for African Americans, several academic majors were negatively associated with persistence and there were no positive associations. These findings raise questions about engagement in academic programs and whether the content of major programs meets the expectations of African Americans. Since these analyses control for preparation and achievement, it simply is not possible or appropriate to reduce these findings to ability or preparation differences. Instead, these findings point to serious academic problems in Indiana higher education. Faculties in health, business, education, and computer science in particular need to consider why their majors do not support persistence by diverse students. (pp. 377-378)
\end{abstract}

Until the academic community digs beneath the surface of these challenges, it won't be possible to know whether the problem is prejudice or just a failure to generate new knowledge and to act in new ways. Pondering this situation in Indiana, the possibility of latent prejudice lingers, especially as long as faculty fail to consider options. St. John and colleagues continue, "This atmosphere of unintended discrimination may exist in Indiana higher education. The fact that, controlling for preparation, college grades, and remedial courses, African Americans in several applied majors-business, education, health, and computer science-do not persist as well as their peers with undeclared majors reveals a serious problem with the engagement of the best and the brightest minority students. The causes cannot be cast off on the lack of parental education or low achievement. The challenge resides within the colleges and universities in the state." (p. 380)

This issue in Indiana illustrates that these challenges can linger indefinitely as long as colleges and universities do not take them seriously. Historically black colleges can be looked to as models for new academic strategies that are more supportive of African Americans (for example, Allen, Epps, and Haniff, 1991; Thomas, 1985), but it also seems critical to begin to build better evaluative information on reform efforts in traditionally white institutions responding to the challenges of serving new clientele. 
The inquiry process had been previously proposed (St. John, 1994, $1995,2003)$ as an approach that could be used to address critical challenges in higher education. The inquiry process involved building an understanding of the challenge, looking internally and externally for possible solutions, evaluating options, developing action plans, implementing plans as pilot tests, and evaluating results, then reengaging in understanding the challenges based on this experience (using a learning cycle). An argument was that some problems required exploration as to why a challenge existed in the first place, before beginning the process of looking externally at research and practice. An adaptation of this approach was proposed for faculty (Paulsen and St. John, 2002) as a means of improving faculty engagement in research on teaching and retention and for linking educational improvement with internal resource acquisition within universities that had incentive budgeting systems.

These arguments informed the initial model for IPAS, which was designed to start with research on persistence and to engage campuses in inquiry that addressed critical challenges they identified. Thus, the IPAS project represents an opportunity to learn about a new approach to organizational change, one that focuses on the most critical challenges.

\section{Introducing Action Inquiry}

The action inquiry process used in the IPAS project started with assessments using statewide data systems to identify statewide and campus-level challenges. Fifteen Indiana campuses were initially involved-seven campuses of Indiana University, four community college campuses, a regional campus of the Purdue University system, two state universities, a public two-year campus, and two private colleges. Teams from each of the campuses attended the initial meeting, but participation became a problem: the project would have required extra time from professional staff whose time was heavily committed.

Initially, the statewide assessment started with the 2000 cohort, examining preparation, college choices, and persistence. We had assumed that the transitions between high school and college would be a major concern in the project, given the emphasis on changes in high school preparation in the state. These analyses were not well received by many of the campuses for a couple of reasons: the analyses were not easy to understand even by people who had a background in statistics, and many of the campuses were more concerned about nontraditional-age students than the college-age cohort. The project team adapted, generating more studies and spending more time explaining them to campus teams. In addition, efforts were made to introduce the assessment and inquiry process. By the end of the assessment process, it had become clear that the state system was facing two major challenges: ensuring equal opportunity for students of color and enabling continuing enrollment by the burgeoning number of working students in the state. 
The training provided workshops to introduce the inquiry process, summarized in the following steps:

1. Build an Understanding of the Challenge. Consider why the challenge exists. What solutions have been tried in the past, and how well did they work? What aspects of the challenge have not been adequately addressed? What aspects of the challenge require more study? Develop hypotheses about the causes for the challenges using data to test the hypotheses. Do the explanations hold up to the evidence? What more preparation might help students in your major programs?

2. Look Internally and Externally for Solutions. Talk with people on campus about how they have addressed related challenges. Consider best practices for retention and how they might be adapted to meet local needs. Visit other campuses that have tried out different approaches to the problem. How well would these alternatives address the challenge at your campus?

3. Assess Possible Solutions. Consider alternatives in relation to the understanding of the problem developed in Step 1. Will the solutions address the challenge at your campus? How can the solution be pilot tested? If you tried out the solution, how would you know if it worked? What information would you need to know how well it worked?

4. Develop Action Plans. Action plans should address the implementation of solutions that should be pilot tested. Consider solutions that can be implemented by current staff. If there are additional costs, develop budgets for consideration internally and externally. (Remember, seeking additional funds can slow down the change process.) Develop action plans with time frames for implementation and evaluation.

5. Implement Pilot Test and Evaluate. Provide feedback to workgroups and campus coordinating team. Use evaluation results to refine the solution. Also, evaluation can be used as a basis for seeking additional funding from internal and external sources, if needed.

The workshops focused on the first two steps of the process. After the workshops, students and staff working on the IPAS project conducted literature reviews to assist with the process of looking externally for solutions. In a few instances, campus teams made site visits to other campuses. In addition, external project advisors were brought to Indiana to provide workshops on topics that appeared to be of interest to all campuses, including working students, faculty inquiry, minority student persistence in scientific fields, and transfer and articulation.

The campus-level view of the inquiry process is presented in Figure 5.1. Campuses were encouraged to review state analyses in comparison to the campus-level studies they were provided. During the first year, statewide meetings were conducted on minority retention, transfer and articulation, and organizing the inquiry process. Participation at these 
Figure 5.1. IPAS Campus Inquiry Model

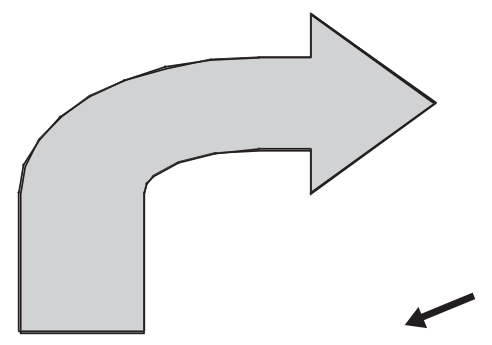

Challenge Area

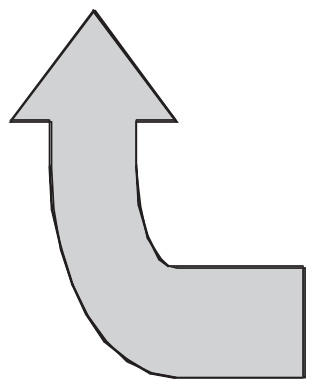

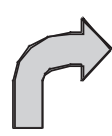

Pilot Testing \& Evaluating

\section{Assessment}

Examining Data

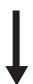

Organizing

Identifying

Challenges

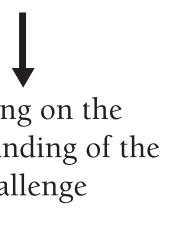

Challenge Area

Identifying

Possible Solutions

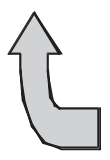

Developing Action Plans

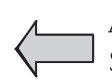

Assessing Solutions

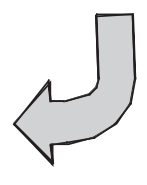

meetings was variable, but a group of interested people emerged at about half of the campuses.

Not all campuses attended regional training, nor did all campuses actively engage in the IPAS process. One private college dropped out before the training on inquiry. They already had a few large, funded projects, and because this one did not include funding they did not want to proceed. After participating in the second round of training, the two state universities and one of the public two-year campuses dropped out and did not participate in subsequent sessions. We expect that the labor-intensive nature of the change process, inconsistent technical support, and lack of resources were reasons for disengaging. (During the first year, the project had the equivalent of two and a half professional staff and one and a half graduate assistants. The project team relied on student volunteers to provide technical support in some instances. The process took more time than either student volunteers or some campus participants could manage.) College administrators and faculty often expect external funding for participation in projects, and involvement in unfunded projects requires volunteers. The main campus of the IU system and two regional campuses lacked any consistent involvement. While our original design called for more extensive involvement of campuses, a more sporadic model of engagement evolved. 
In spite of these obstacles, nine out of sixteen campuses have participated in the process, developing one or more active workgroups engaged in inquiry, as shown in Table 5.1. In each of these groups, teams have been involved in using action inquiry to address challenges they identified. The research we conducted provided their baseline information, but the challenges reflect their concerns. Although the extent of involvement was less than originally envisioned, we knew going into the project that our project was staffed at a level that might support only four or five campuses. The fact that we had active engagement at nine campuses represented a step forward, an opportunity to learn more together about how to use action inquiry to address critical challenges.

In addition to providing workshops on a method of inquiry, the IPAS team provided technical assistance with the inquiry process. This assistance

Table 5.1. Challenges Chosen for Action Inquiry at Partner Campuses

\begin{tabular}{|c|c|c|}
\hline Partner Campus & Campus Type & Critical Challenges \\
\hline $\begin{array}{l}\text { Indiana University } \\
\text { Northwest }\end{array}$ & Four-year regional, public & $\begin{array}{l}\text { 1. Undecided students } \\
\text { 2. Supplemental instruction } \\
\text { 3. Critical Literacy Program } \\
\text { (remedial students) } \\
\text { 4. Working students }\end{array}$ \\
\hline $\begin{array}{l}\text { Purdue University } \\
\text { Calumet }\end{array}$ & Four-year regional, public & $\begin{array}{l}\text { 1. Working students } \\
\text { 2. Supplemental instruction } \\
\text { 3. Academic Recovery Program }\end{array}$ \\
\hline Ivy Tech Northwest & Two-year, public & $\begin{array}{l}\text { 1. First-Year Experience } \\
\text { 2. Working students } \\
\text { 3. Tutoring }\end{array}$ \\
\hline Indiana Wesleyan & Four-year, private & $\begin{array}{l}\text { 1. Center for Life Calling and } \\
\text { Leadership }\end{array}$ \\
\hline $\begin{array}{l}\text { Indiana University } \\
\text { East }\end{array}$ & Four-year regional, public & $\begin{array}{l}\text { 1. 21st Century Scholars } \\
\text { 2. Sophomore persistence }\end{array}$ \\
\hline Ivy Tech Richmond & Two-year, public & $\begin{array}{l}\text { 1. Remedial education } \\
\text { 2. Financial aid } \\
\text { 3. Academic support }\end{array}$ \\
\hline IUPUI & Four-year regional, public & $\begin{array}{l}\text { 1. Transfer program } \\
\text { 2. Diversity and curriculum }\end{array}$ \\
\hline $\begin{array}{l}\text { Indiana University } \\
\text { Kokomo }\end{array}$ & Four-year regional, public & 1. Learning communities \\
\hline Ivy Tech Central & Two-year, public & $\begin{array}{l}\text { 1. Diverse students } \\
\text { 2. Academic advising } \\
\text { 3. IR capacity building } \\
\text { 4. Transfer program }\end{array}$ \\
\hline
\end{tabular}


included involvement at meetings on the campuses, writing literature reviews for campus teams exploring topics or to summarize research on best practices, holding and analyzing focus group interviews, and conducting evaluation analyses that used data merged from campus records and the state data system. This ongoing technical assistance was invaluable to the process and made it possible for the willing to make progress.

\section{Case Examples}

During the 2004-05 academic year, workgroups on the nine campuses engaged in inquiry on the challenge topics. The extent of involvement varied. One relatively small, multicampus community college-Ivy Tech Northwest-was intensively involved, as were workgroups at other campuses. Many of the issues addressed by the working groups dealt with responding to the needs of students differently than in the past and started with building an understanding of the problem.

Two forms of building an understanding of a challenge emerged among the campuses, as shown in Figure 5.2. When workgroups chose challenge areas with a history, it was often possible to start with the evaluation process, creating a mini-inquiry. However, when the problems were new, then the workgroups started at the beginning of the cycle and looped through the inquiry process. Although most campuses chose local challenges, a few instances of multicampus collaboration emerged. Three patterns emerged among the working groups:

- Inquiry into challenge areas with a history at the campus, a process that started with an evaluation of current practice (see the small loop in Figure 5.2)

- Inquiry into new topics for which there was little or no history of intervention, necessitating that inquiry be started from the beginning (see the big loop in Figure 5.2)

- Collaboration in addressing challenges shared across campuses, starting either with evaluation of current practice or with building an understanding of new challenges.

\section{Examples of the Evaluation Loop}

Indiana University Kokomo (IUK) had implemented a set of connected courses for first-year students as part of an earlier retention project that had received funding from the IU system. They had modified the learning community concept for commuter students, the clients of this regional campus that did not have dormitories. From the initial workshop on IPAS, the IUK team focused on the evaluation of this venture. The IPAS team conducted focus group interviews with students and a multivariate study of the intervention on retention (described in Chapter Six of this volume). These 


\section{Figure 5.2. Role of Preliminary Evaluation in the IPAS Process for the Short Loop Through Inquiry}

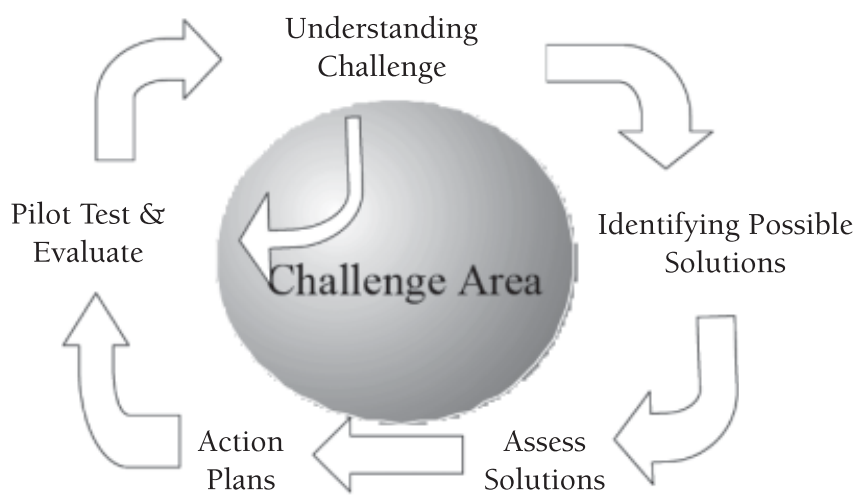

mixed-method evaluation results were important for the campus because the special funding would soon expire and the results could help them with decisions about whether and how to continue with this program, given their budget constraints.

Indiana Wesleyan University chose to focus on a program they had developed to support students who were undecided about their majors. The multiyear process involved exploring personal purpose and interests during the first college year, different forms of engaged learning and leadership during the sophomore and junior years, and job options during the senior year. This project had been funded by the Lilly Endowment and was nearing completion, so it was time to evaluate. In addition, they had had inquiries about their model from many other campuses. They concentrated their IPAS activities on this distinctive program, using IPAS staff to conduct focus group interviews and to complete the multivariate study of the type described in Chapter Six of this volume. The results are being used by the campus in communication with other campuses about their model as well as in internal decisions about the future of the program.

These examples illustrate the small-loop process. By starting with evaluation, the collaborative effort helped to close the loop on prior innovations, building an understanding of possible next steps. In fact, as discussed in Chapter Six, multivariate studies of persistence were conducted for each of the IU campuses as part of the IPAS funding agreement. These evaluations provided information for summer workshops for participants at partner campuses.

Too frequently, campuses that engage in innovations during a grant period have difficulty reallocating internal resources to continue the effort after external funding ends. Integrating sound evaluation methods into the process can inform decision making about whether to continue, how to modify, and how to fund these projects if they have their intended effects. 


\section{Using the Full Inquiry Cycle}

Many of the workgroups addressed new challenges. In these instances, campus teams formed to address challenge areas, starting with the process of building a shared understanding of the problem.

IVY Tech Richmond, a small, two-year college in Richmond, Indiana, focused on challenges related to access and outreach for diverse students, use of state and federal student aid funds, and student understanding of their choices in a college environment. After exploring these challenges, they realized that academic literacy was central to each of these issues. After considering a range of options and realizing that funding was limited, they decided to try out - or pilot test-a new orientation process. Historically, the campus had done very little to inform new students. They designed an orientation that included information on student aid, registration, support services, and related topics. They planned a new orientation for admitted students and designed an instrument to measure student knowledge of the topics covered. They administered the instrument as a pretest and posttest for the new orientation, building baseline for judging how well they did with the new program.

Indiana University-Purdue University Indianapolis (IUPUI) formed a workgroup composed of faculty members from different academic fields who were interested in persistence by diverse students, a topic that had emerged from the review of IPAS research. During 2004-05 the group met with a facilitator to discuss alternative approaches to current practices. By the end of the year, the workgroup had designed interventions for their courses during the next years. Some had designed their own research projects and secured human subject approval for classroom research during the 2005-06 academic years. In addition, the IPAS team worked with the facilitator to provide research support-interviews and quantitative analysesthat could provide evaluations of the process.

As these examples illustrate, not all of the projects would be implemented on a scale that would allow for multivariate statistical analyses and evaluation. Nevertheless, workgroups were encouraged to integrate evaluation into the design of their interventions to understand the effectiveness of their interventions and to plan modifications for future improvements.

\section{Multicampus Collaborations}

During several IPAS workshops involving the three campuses in northwestern Indiana and the regional IU campus in South Bend, administrators at the three Gary-region campuses-Purdue University Calumet, IU Northwest, and Ivy Tech Northwest-formed a collaborative workgroup to address a common challenge: providing educational opportunities for working students. Unlike students at the major state college and research university campuses in the state, students at these campuses tended to be workers first and students second. The team from Purdue Calumet was the first to 
focus on the issue and chose to evaluate their efforts to employ students in supplemental instruction activities, one of their topical areas. As workshop conversations progressed, a collaborative team emerged with members from the three Gary-region campuses. For many years, there had been interest in collaborative projects in the region but none had emerged before IPAS.

The workgroup planned a conference to discuss the challenge, with participation from the three campuses. Then they secured funding from their campuses to conduct a survey of working students to learn about their working situations, their course preferences, and whether they had support for college enrollment. In addition to cosponsoring the conference, the IPAS team completed a literature review on working students (Tuttle, McKinney, and Rago, 2005), a resource that proved helpful in the survey design. This collaboration illustrates sustained effort to build an understanding of a shared problem. Over the longer term, the workgroup hoped to secure support from local businesses and other groups for new programs. However, they realized that their first step involved finding out more about this unique group of students for which there was only limited information from prior students.

The other example of collaboration involved IUPUI and Ivy Tech Indianapolis. While IUPUI had a well-established IR function, they did not have access to data on transfer students. They decided to form an IPAS workgroup with Ivy Tech to evaluate their new collaborative admissions arrangements. Historically, IUPUI had functioned as a nearly open-admissions institution, with a high drop-out rate attributable to academic failures. After the Ivy Tech system began to transition to community college status, IUPUI raised admissions standards. IUPUI referred some applicants to Ivy Tech and delayed admissions until after completion of a preparatory program.

The new workgroup started with a review of this new admissions arrangement. To support this collaborative workgroup, the IPAS team analyzed the college enrollment patterns of students who had been deferred from IUPUI for academic reasons, building a basic descriptive understanding of the impact of the new admissions procedure. In addition, IPAS convened a statewide meeting on articulation and transfer with an external consultant to facilitate a shared understanding of best practice. With this background, the workgroup began the process of exploring the next steps that could be taken to build on this foundation.

\section{From Inquiry to Action}

At the midpoint of an action research project, it simply is not possible to reach summative conclusions. In particular, we do not yet know if the project will encourage or enable change at the participating campuses or if the model can be replicated-though we would like to think we will achieve these aims. A great deal has been learned, even if we are uncertain about the ultimate outcomes. At this point, we can only summarize what we have learned about research-informed reform. 
It is evident that an inquiry model has been used by some campuses to address the challenges they identified. Three major themes seem to run through the efforts, all of which relate to the extensive research conducted with the state database. One theme is supporting diversity on the campuses. There is a growing realization that there is a need to focus on the core academic mission, from the academic literacy of first-generation students (the Ivy Tech Richmond project) to engagement of faculty in innovations in their courses (IUPUI faculty workgroup). Second, many of the new students coming to Indiana campuses are from working-class families. Efforts to engage students on campuses (IU Kokomo learning communities) and to study working students on their own terms (the northwestern region collaboration) illustrate new ventures aimed at addressing the learning needs of this new clientele. Finally, the integration of formal evaluation as a capstone activity for innovative projects represented a major step forward for most of the campuses in the state.

The current challenge for IPAS is to design interventions that can be pilot tested and evaluated by the end of the project. An intensive effort is now being made (summer 2005) to refine plans for interventions. To complete the process as originally envisioned, more of the collaborating campuses will need to move through the action planning process, to implement new innovative projects as pilot tests that can be evaluated. The intent of the project has been to implement well-designed interventions during the 2005-06 academic year, enabling data collection as an integral part of the evaluations (interviews along with empirical data on participation), so that it will be possible to complete a new set of evaluations of students during the final term of the three-year project (fall term of 2006). Whether or not new projects will be implemented during this time frame still remains to be seen.

One of the major lessons learned from the project is that inquiry involves collaboration between institutional researchers and campus workgroups. The pattern of learning at the campuses has been enhanced by collaborations with researchers from the IPAS team. During the summer of 2005 a statewide workshop was conducted that provided opportunities for the collaborating campuses to present the results of their work to date. Some had completed a complete inquiry cycle, while others were still trying to get started. However, it was clear by the end of the meeting that most of the successful ventures had involved collaborations between campus groups and IPAS researchers who provided technical assistance. The collaborative nature of the project reflected the spirit of collaboration advocated by Hansen and Borden in Chapter Four of this volume. Indeed, after a year and a half we had come full circle. (The papers presented as Chapters One, Two, and Four of this volume had been presented at the initial workshop in January 2004. The issues-limited use of formal evaluation and the need for collaboration-had been discussed extensively, often in heated ways.) At the outset we had understood, conceptually at least, that the project was collaboration. By the midpoint, the summer of 2005, the meaning of and potential for collaboration were understood in a more practical way by one and all. It was 
no longer theory. Most of us understood that the breakthrough resulted from the collaboration. The new ideas came from efforts to understand past efforts coupled with critical thinking about the real lives of students.

A second lesson relates to evaluation, another starting point for the project understood better with time. At the initial meeting in January 2004, there was a division between researchers and practitioners. The data were somewhat intimidating to practitioners who lacked training in statistics. And the graduate students and researchers were not yet engaged. By the summer of 2005, when a new set of evaluations was presented, most of the participants understood the importance of the work. Many practitioners spoke about how the literature reviews and evaluation results were being used in decision-making processes on campuses. The researchers had come to understand the utility of applied research. It was no longer ethereal; both practitioners and researchers shared a commitment to working together, at least so it seemed as the midproject meeting came to a close.

Finally, it is also evident that the state-level databases have substantial value for research on college students, but there is a need to use research to support change and improvement. The Indiana Commission for Higher Education had for many years collected student records with information on high school curriculum, SAT scores, and college majors, grades, and student aid. There had been a few prior studies using these data, but their potential utility had not been fully tapped. As part of IPAS, this database was used for state- and campus-level analyses. Campuses could compare their results to those of the state as a whole. They could also explore new topics, such as transfer and retention by minority students. While the many tables generated in the process usually did not captivate the interest of practitioners, the new bottom lines-the findings-generally were understood. It was relatively easy to pick up a few key points from both sets of analyses. Typically, these understandings were situated within the interests of the individuals and sometimes were commonly understood among team members. But more important, it became evident that research could help practitioners build an understanding of the challenges about which they had nagging concerns, providing the starting point for inquiry.

\section{References}

Allen, W. R., Epps, E. G., and Haniff, N. Z. (eds.). College in Black and White: African American Students in Predominantly White and in Historically Black Public Universities. Albany, N.Y.: SUNY Press, 1991.

Balderston, F. E. Managing Today's University. San Francisco: Jossey-Bass, 1974.

Banta, T. W., Rudolph, C. B., Van Dyke, J., and Fisher, H. S. "Performance Funding Comes of Age in Tennessee." Journal of Higher Education, 1996, 67, 23-45.

Chaffee, E. E. "Role of Rationality in University Budgeting." Research in Higher Education, 1983, 19(4), 387-406.

Cheit, E. F. The New Depression in Higher Education: Two Years Later. New York: McGraw Hill, 1974. 
Habermas, J. Theory of Communicative Action. Vol. 1: Reason and the Rationalization of Society. Boston: Beacon Press, 1984.

Habermas, J. The Theory of Communicative Action. Vol. 2: Lifeworld and System: A Critique of Functionalist Reasoning (T. McCarthy, trans.). Boston: Beacon Press, 1987.

Habermas, J. The Structural Transformation of the Public Sphere: An Inquiry into a Category of Bourgeois Society. Cambridge, Mass.: MIT Press, 1991.

Halstead, D. K. Statewide Planning in Higher Education. Washington, D.C.: U.S. Government Printing Office, 1974.

Keller, G. Academic Strategy: The Management Revolution in American Higher Education. Baltimore: Johns Hopkins University Press, 1983.

Norris, P. M., and Poulton, N. L. A Guide for New Planners. Ann Arbor: Society for College and University Planning, 1987.

Paulsen, M. B., and St. John, E. P. "Budget Incentive Structures and the Improvement of College Teaching." In D. M. Priest and others (eds.), Incentive-Based Budgeting Systems in Public Universities. Northampton, Mass.: Edward Elgar, 2002.

St. John, E. P. Prices, Productivity, and Investment: Assessing Financial Strategies in Higher Education. ASHE-ERIC Higher Education Report, no. 3. Washington, D.C.: George Washington University, School of Education and Human Development, 1994.

St. John, E. P. "Rethinking Tuition and Student Aid Strategies." In E. P. St. John (ed.), Rethinking Tuition and Student Aid Strategies. New Directions for Higher Education, no. 89. San Francisco: Jossey-Bass, 1995.

St. John, E. P. Refinancing the College Dream: Access, Equal Opportunity, and Justice for Taxpayers. Baltimore: Johns Hopkins University Press, 2003.

St. John, E. P., Carter, D. F., Chung, C. G., and Musoba, G. D. "Diversity and Persistence in Indiana Higher Education: The Impact of Preparation, Major Choices, and Student Aid.” In E. P. St. John (ed.), Readings on Equal Education. Vol. 21: Public Policy and Educational Opportunity: School Reforms, Postsecondary Encouragement, and State Policies on Higher Education (pp. 359-410). New York: AMS Press, 2006.

Thomas, G. E. "College Major and Career Inequality: Implications for Black Students." Journal of Negro Education, 1985, 54, 537-547.

Tuttle, T., McKinney, J., and Rago, M. College Students Working: The Choice Nexus-A Review of Research Literature on College Students and Work. IPAS Topic Brief. Bloomington: Indiana Project on Academic Success, 2005.

Weathersby, G. B., and Balderston, F. E. "PPBS in Higher Education Planning and Management: Part I, An Overview." Higher Education, 1972, 1, 191-206.

EDWARD P. ST. JOHN is Algo D. Henderson Collegiate Professor of Education at the Center for the Study of Higher and Postsecondary Education at the University of Michigan. His research focuses on educational policy and public finance in both K-12 and higher education.

JEFFREY S. MCKINNEY is associate director of the Indiana Project on Academic Success. He holds a Ph.D. in higher education and student affairs from Indiana University.

TINA TUTTLE, a former student services administrator, is a doctoral candidate at Indiana University with research interests in college access, working students, nontraditional adult students, student financial aid, and veterans' educational attainment. 